\title{
Host-derived gene silencing of parasite fitness genes improves resistance to soybean cyst nematodes in stable transgenic soybean
}

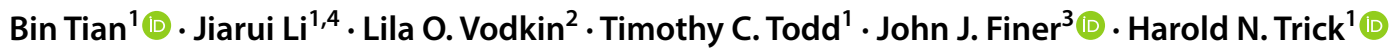

Received: 15 October 2018 / Accepted: 14 June 2019 / Published online: 22 June 2019

(c) The Author(s) 2019

\begin{abstract}
Key message Soybean expressing small interfering RNA of SCN improved plant resistance to SCN consistently, and small RNA-seq analysis revealed a threshold of siRNA expression required for resistance ability.

Abstract Soybean cyst nematode (SCN), Heterodera glycines, is one of the most destructive pests limiting soybean production worldwide, with estimated losses of $\$ 1$ billion dollars annually in the USA alone. RNA interference (RNAi) has become a powerful tool for silencing gene expression. We report here that the expression of hairpin RNAi constructs, derived from two SCN genes related to reproduction and fitness, HgY25 and HgPrp17, enhances resistance to SCN in stably transformed soybean plants. The analyses of $\mathrm{T}_{3}$ to $\mathrm{T}_{5}$ generations of stable transgenic soybeans by molecular strategies and next-generation sequencing confirmed the presence of specific short interfering RNAs complementary to the target SCN genes. Bioassays performed on transgenic soybean lines targeting SCN HgY25 and HgPrp17 fitness genes showed significant reductions (up to $73 \%$ ) for eggs/g root in the $\mathrm{T}_{3}$ and $\mathrm{T}_{4}$ homozygous transgenic lines. Targeted mRNAs of SCN eggs collected from the transgenic soybean lines were efficiently down-regulated, as confirmed by quantitative RT-PCR. Based on the small RNAseq data and bioassays, it is our hypothesis that a threshold of small interfering RNA molecules is required to significantly reduce SCN populations feeding on the host plants. Our results demonstrated that host-derived gene silencing of essential $\mathrm{SCN}$ fitness genes could be an effective strategy for enhancing resistance in crop plants.
\end{abstract}

\section{Introduction}

Soybean cyst nematode ( $\mathrm{SCN})$, Heterodera glycines, is one of the most economically important biotic stresses in global soybean production, causing more than $\$ 1$ billion dollars

Communicated by Henry T. Nguyen.

Electronic supplementary material The online version of this article (https://doi.org/10.1007/s00122-019-03379-0) contains supplementary material, which is available to authorized users.

Harold N. Trick

hnt@ksu.edu

1 Department of Plant Pathology, Kansas State University, 1712 Claflin Road, Manhattan, KS 66506, USA

2 Department of Crop Sciences, University of Illinois, 1201 W. Gregory Drive, Urbana, IL 61801, USA

3 Department of Horticulture and Crop Science, OARDC, The Ohio State University, 1680 Madison Ave, Wooster, OH 44691, USA

4 Present Address: Innatrix Inc, 6 Davis Drive, Research Triangle Park, NC 27709, USA in yield losses annually in the USA alone (Koenning and Wrather 2010). Although the use of resistant cultivars has been the most effective management strategies for SCN controls in the past, sources of genetic resistance used in commercial soybean production are limited and various virulent nematode populations are beginning to emerge as resistance breaks down (Klink and Matthews 2009). Breeding for resistance to SCN remains highly challenging due to the limited availability of SCN-resistant genes and because the mechanism of soybean resistance to $\mathrm{SCN}$ is still unclear (Gillet et al. 2017; Liu et al. 2017). Alternative novel approaches are needed to provide resistance to this widespread and destructive soybean pest.

Since it was first demonstrated in Caenorhabditis elegans (Fire et al. 1998), RNA interference (RNAi) has emerged as an efficient tool for knocking down transcript levels of specific target genes. Over the past two decades, many studies have successfully applied the strategy of host-delivered RNAi to reduce pathogen infection. The effectiveness of host-derived RNAi strategies has been demonstrated in controlling a wide range of plant parasitic insects, fungi, and nematodes (Bolognesi et al. 2012; Cheng et al. 2015; 
Fairbairn et al. 2007; Govindarajulu et al. 2015; Huang et al. 2006; Sanju et al. 2015; Yadav et al. 2006; Zhang et al. 2015). Furthermore, RNAi experiments targeting SCN have shown similar encouraging results. For SCN infection, pre-parasitic second-stage juveniles (pre-J2) of SCN initiate the infection by invading the plant vascular cylinder. Syncytia are induced on soybean roots by parasitic (par)-J2 and J3 SCN that usually have a swollen body shape and rounded tail compared to pre-J2. J4/adult females with a near lemon shape keep feeding on plant roots until eggs develop (Sobezak and Golinowski 2009). For initial efforts to use RNAi to control SCN, soaking $H$. glycines infective juveniles in RNAi solutions of a conserved ribosomal gene ( $\mathrm{Hg}$ $r p s-23)$ resulted in sterile and sick nematodes as shown by positive Sytox fluorescence (Alkharouf et al. 2007). Transgenic soybean lines expressing dsRNA of a gene coding for Major Sperm Protein of $H$. glycines reduced eggs $\mathrm{g}^{-1}$ root tissue up to 68\% (Steeves et al. 2006). In planta expression of SCN homologs of several genes with lethal mutant phenotypes in C. elegans significantly reduced the ability of $H$. glycines females to mature (Klink et al. 2009). Previous studies from our laboratory reported diminished $\mathrm{H}$. glycines egg production by up to $95 \%$ using soybean hairy roots expressing siRNAs for several additional genes involved in reproduction and/or development ( $\mathrm{Li}$ et al. 2010, 2009). It appears that a potentially large reservoir of essential and specific nematode genes may be available for use in hostderived RNAi strategy against nematode infection.

Limitations of the host-derived RNAi strategy include efficient delivery of siRNA molecules to target pathogens and the effectiveness of these molecules in triggering the RNAi pathway in those pathogens ( $\mathrm{Li}$ et al. 2011). To date, the effectiveness of nematode control using this strategy has been variable (Klink et al. 2009; Kumar et al. 2017; Sindhu et al. 2009; Vieira et al. 2015). To achieve new and stable resources for SCN resistance in soybean breeding programs and to demonstrate consistent effects against SCN, we obtained stable transgenic soybean plants expressing RNAi silencing vectors and analyzed the small interfering RNA(siRNA) expression levels in multiple lines via small RNA-seq. In the present study, two targeted SCN developmental genes were evaluated, $\mathrm{H}$. glycines gene $\mathrm{HgY} 25$ (NM_062040), encoding a beta subunit of a coatomer (COPI) complex, and HgPrp-17 (AF113915), encoding a pre-mRNA splicing factor. Studies on the homologous genes in C. elegans indicated that both genes are required for fertility, adult viability, proliferation and meiotic development (Kamath et al. 2003; Nickel et al. 2002; Kerins et al. 2010). In addition, both genes were identified as suitable targets for RNAi-based resistance in our previous study with composite plants (Li et al. 2010). Analysis of the siRNA sequence profile via deep sequencing confirmed that the dsRNAs of both $\mathrm{HgY} 25$ and HgPrp-17 were expressed in transgenic plants and were cleaved into overlapping 20-24 nt siRNA molecules. The two most effective RNAi transgenic lines of each target gene were selected from approximately 16 transgenic events, and homozygous $\mathrm{T}_{4}$ generations were obtained. Bioassays confirmed that each of these stable transgenic lines continued to display significant reductions in numbers of SCN cysts and eggs. Additionally, and to the best of our knowledge, we report for the first time a correlation between host-induced siRNA expression and the level of SCN resistance. Our data suggest a threshold level of siRNA molecules was required to significantly reduce $\mathrm{SCN}$ populations feeding on the host plants. Our results add to the growing body of evidence supporting the use of host-induced RNAi as an effective strategy for SCN management and breeding programs. In addition, the siRNA expression data presented here provide valuable information for advancing plant pest or pathogen control approaches more generally through the expression of target siRNA sequences of pests or pathogen genes in host plants.

\section{Materials and methods}

\section{Cloning of HgY25 and RNAi construct}

HgY25 (Genbank Accession No. CB824330) from H. glycines was identified from datasets in nematode.net. Using H. glycines HG type 2.7 cDNA as template, a 292-bp fragment of $\mathrm{HgY25}$ was obtained by PCR with specific primers Y25-F and Y25-R (Table S1). Y25-F and Y25-R were also used to amplify the $\mathrm{HgY} 25$ gene from HG type 7 and HG type 1.3.5.6.7 of $\mathrm{H}$. glycines. The 3' race of $\mathrm{HgY} 25$ was performed according to the instructions of GeneRacer® Kit (Invitrogen, Carlsbad, CA). We recovered a 1101 bp of HgY25 (Genbank Accession No. HM369132), including the 872 bp coding region and 229-bp 3' UTR. A 383 bp fragment of the HgPrpl7 gene was obtained with primers Prp17$\mathrm{F}$ and Prp17-R (Table S1). The binary vector pANDA35HK was a kind gift from Ko Shimamoto (Miki and Shimamoto 2004). The pANDA35HK RNAi vector has an RNA interference cassette under the control of the constitutive $35 \mathrm{~S}$ cauliflower mosaic virus (CaMV35S) promoter. This vector contains the nptII gene that confers resistance to kanamycin, and a hygromycin phosphotransferase gene ( $h p t)$ both driven by a CaMV35S promoter. Cloning of the PCR products into pANDA35HK was performed as described previously ( $\mathrm{Li}$ et al. 2009). Briefly, both PCR products were first ligated into pGEM-T Easy vector and then subcloned into pENTR4 vector by EcoRI restriction sites. Subsequently, the pENTR4 vector carrying $\mathrm{HgY} 25$ was recombined with pANDA35HK vector using LR clonase (Invitrogen, Carlsbad, CA). The resulting RNAi expression vectors, pANDA35HK_Y25 and pANDA35HK-Prp 17 contained the 292 bp and $383 \mathrm{bp}$ 
gene fragments, respectively, in complementary orientation, separated by 930-bp GUS linker fragment, and driven by the CaMV35S promoter (Fig. 1).

\section{Stable transformation of soybean mediated by bombardment}

The soybean cultivar "JackX" (Jack X PI417138) was used for transformation (kind gift from Dr. Wayne Parrott at the University of Georgia). This line had been chosen as the model genotype for SCN gene-silencing experimentation, is susceptible to $\mathrm{SCN}$, and is amenable to transformation. Soybean somatic embryos were initiated and maintained according to Finer and McMullen (1991). Soybean embryos of cultivar "JackX" were bombarded with DNA-coated tungsten particles with a Particle Inflow Gun (Finer et al. 1992). Following the transformation procedure, hygromycin was used in the embryo proliferation medium to select for tissue expressing the plasmid pANDA35HK Y25 and Prp17 containing the $h p t$ gene. Selection and regeneration for soybean transformation were performed as described by Trick et al. (1997).

\section{Identification of transgenic soybean plants by PCR, reverse transcription PCR (RT-PCR), and qRT-PCR}

Plant DNA from young soybean leaves was extracted by E.Z.N.A® Plant DNA Kit (Omega Bio-tek Inc., Norcross, GA, USA) following the manufacturer's instruction. The genomic DNA (gDNA) quality was examined by the NanoDrop ND-1000 Spectrophotometer (Nanodrop Technologies, Wilmington, DE, USA) and PCR with gene-specific primers for the Ribosomal S21 gene (Rib-F and Rib-R) (Li et al. 2010). The Gus-F1 and Gus-R2 primers situated within the GUS linker of the RNAi construct, and they were used to identify the presence of sense and antisense fragments in expression RNAi constructs. The Gus-R2 primer was paired with Y25-R or Prp17-R for amplification of GmY25 or GmPrp17 sense fragments, and Gus-F1 was paired with Y25-R or Prp17-R for amplification of GmY25 or GmPrp17 antisense fragment. PCR cycling comprised an initial step at $94{ }^{\circ} \mathrm{C}$ for $3 \mathrm{~min}$, followed by 32 cycles at $94{ }^{\circ} \mathrm{C}$ for $30 \mathrm{~s}$, $58{ }^{\circ} \mathrm{C}$ for $30 \mathrm{~s}$, and $72{ }^{\circ} \mathrm{C}$ for $45 \mathrm{~s}$.

Total RNAs from transgenic soybean plants were isolated using TRIzol reagent (Invitrogen, CA, USA) according to manufacturer's instructions. The eggs of nematodes feeding on plants were pooled and collected with three biological replications in each experiment, and total RNA was extracted following the protocol described by Tian et al. (2016). For reverse transcription PCR (RT-PCR), $1 \mu \mathrm{g}$ of total RNA was treated with DNase I (Promega, Madison, WI) and reverse-transcribed using Reverse Transcription System kit (Promega, Madison, WI) following the manufacturer's instructions. The detection of target gene expression was conducted using the same protocol as described above. Quantitative PCR was performed on the CFX96 Touch ${ }^{\mathrm{TM}}$ Real-Time PCR Detection system (Bio-Rad, Hercules, CA, USA) using $\mathrm{iQ}^{\mathrm{TM}} \mathrm{SYBR}{ }^{\circledR}$ Green Supermixes (Bio-Rad). The qPCR program was set up with one cycle for template denaturation and hot start Taq activation at $95^{\circ} \mathrm{C}$ for $2 \mathrm{~min}$, then 40 cycles of $95^{\circ} \mathrm{C}$ for $5 \mathrm{~s}$, and $60^{\circ} \mathrm{C}$ for $20 \mathrm{~s}$ extension step with dissociation. The conserved $H$. glycines $\beta$-actin (AF318603) was used as the internal control in nematodes (Tian et al. 2016). The RT-qPCR reaction was done following the manufacturer's protocol with three biological and three technical replicates for each sample. The relative target gene expression was calculated using the $2^{-\Delta \Delta C T}$ method (Livak and Schmittgen 2001) for all SCN samples. All primers used are listed in Table S1.

\section{Small RNAs sequencing from transgenic plants}

All transgenic plants were grown in the greenhouse at $26{ }^{\circ} \mathrm{C}$ and $16 / 8$ day/night photoperiod. During the bioassays, either leaves and/or roots were collected, flashfrozen in liquid nitrogen, and stored at $-80{ }^{\circ} \mathrm{C}$ for further analysis. Plant tissues were then freeze-dried and total RNA was isolated as previously described (Tuteja et al. 2009). A small RNA library was prepared with an Illumina Small RNA version 1.5 Sample Prep Kit and sequenced by synthesis using the Illumina GAIIx at the Keck Center of the University of Illinois. After trimming the $3^{\prime}$ adapter, sequences retaining greater than $16 \mathrm{nt}$

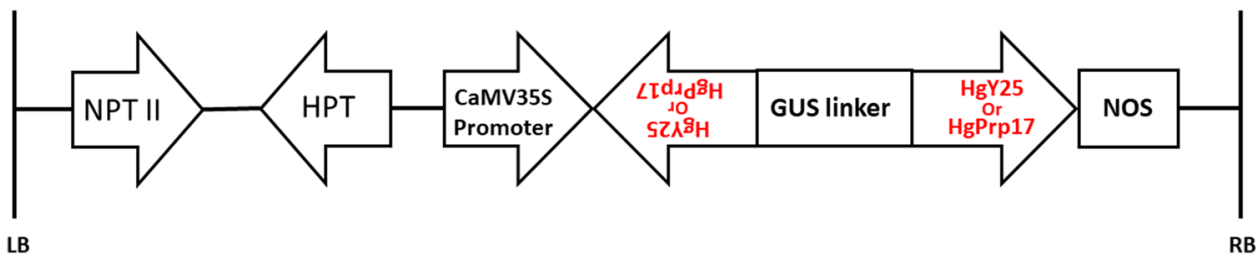

Fig. 1 The structure of the RNAi constructs used for transformation. The backbone vector is pBI121. The red indicates the fragment positions of either $\mathrm{HgY} 25$ or $\mathrm{HgPrp} 17$ introduced into the construct as inverted repeats. The NPT II and HPT cassettes are selection markers for kanamycin resistance and hygromycin resistance, respectively (color figure online) 
were compared to obtain the unique sequences and the number of occurrences of each distinct sequence. Alignments of small RNAs to target genes sequences were performed using Bowtie v1 (Langmead et al. 2009) allowing no mismatches. Bowtie outputs were further filtered to retain sequences from 18 to $25 \mathrm{nt}$ to plot size distributions, alignments to the target sequence, and calculate read per million (RPM) values (reads aligned per million total sequence reads). All plant samples selected in bioassays for small RNAs sequencing are listed in Tables S2-S4.

\section{SCN bioassay}

To explore suppression of nematode reproduction in transgenic plants expressing dsRNA of HgY25 and $\mathrm{HgPrp} 17$ genes, transgenic seeds were planted individually in D40 Deepots (Stuewe and Sons, Inc., Corvallis, OR) containing a SCN HG type 7-infested sand-soil mix with approximately 4500 eggs per $100 \mathrm{~cm}^{3}$ of soil. The nematode population originated from a naturally infested commercial soybean field in Cherokee Co., KS, and was maintained on a susceptible soybean variety, KS3406RR, under greenhouse conditions. The non-transgenic, susceptible soybean cultivar JackX was used as negative control. Bioassays were performed on transgenic plants and negative controls as described by Tian et al. (2016). In initial $\mathrm{T}_{1}$ generation screening bioassays, a total of 12 seeds (four biological replicates in each of three bioassay experiments) for each event were randomized and planted in individual D40 Deepot containing the SCN infested soil. The same number seeds of susceptible cultivar JackX and resistant cultivar KS4313N were also included in each assay as controls. In subsequent $\mathrm{SCN}$ bioassays, $15\left(\mathrm{~T}_{2}-\mathrm{T}_{3}\right.$ generation) to $20\left(\mathrm{~T}_{3}-\mathrm{T}_{4}\right.$ generation) plants of transgenic lines whose expression were confirmed by both PCR and RT-PCR, and which showed significant effects in $T_{1}$ generation bioassays, were evaluated in one $\left(\mathrm{T}_{2}-\mathrm{T}_{3}\right.$ generation) to three $\left(\mathrm{T}_{3}-\mathrm{T}_{4}\right.$ generation) independent experiments. After five weeks post-inoculation, the soil was washed from the plant roots, and the cysts and eggs were collected and counted as previously described (Li et al. 2009). The root dry weights were measured for each root after one week in a $50{ }^{\circ} \mathrm{C}$ drying room. Numbers of cysts and eggs were counted under the microscope and normalized as cysts/g root, eggs/g root. Data from bioassays were subjected to analysis of variance with the GLM procedure in SAS (SAS Institute, Cary, NC, USA).

\section{Results}

\section{Hereodera glycines HgY25 and HgPrp17 genes and RNAi vector construction}

A 1101-bp nucleotide sequence of the $\mathrm{HgY} 25$ gene (GenBank accession No. HM369132) was cloned and obtained from nematode cDNA by RACE-PCR. This sequence included the 876-bp open reading frame (ORF) region encoding 291 amino acids and a 225-bp 3' un-translated region (UTR). The selected 292-bp sequence, used in the RNAi construct, was highly conserved among different $H$. glycines populations (Fig. S1a) and displayed more than $99 \%$ homology among three populations of HG type 2.7, HG type 7, and HG type 1.3.5.6.7. The $\mathrm{HgY25}$ gene had limited similarity with beta subunit of the COPI complex from C. elegans and other species (Fig. S1b). The H. glycinesPrp-17 gene (GenBank accession No. AF113915) encodes a pre-mRNA splicing factor, and it was selected based on previous results in transgenic hairy roots (Li et al. 2010). To efficiently generate specific siRNAs against both $\mathrm{SCN}$ genes in transgenic soybean plant, the inverted repeats of $292 \mathrm{bp}$ HgY25 and 383 bp HgPrp17 were independently cloned into the pANDA35HK vector (Miki and Shimamoto 2004) by Gateway cloning. Therefore, the resulting RNAi expression vectors pANDA35HK-Y25 and pANDA35HK-Prp17 contained both antisense and sense fragments of the target genes, separated by a 930-bp GUS linker fragment, and regulated by the constitutive CaMV35S promoter and the NOS terminator (Fig. 1).

\section{Molecular analysis of transgenic soybean plants expressing RNAi constructs}

Soybean embryos were transformed with RNAi constructs containing either pANDA35HK-Y25 or pANDA35HK-Prp17 by particle bombardment to generate transgenic soybean plants as previously described (Steeves et al. 2006). All $\mathrm{T}_{0}$ plants were tested for the presence of the gene of interest (GOI) and the hygromycin resistance gene by PCR. $\mathrm{T}_{1}$ seeds were harvested from a total of 9 RNAi GmY25 and 7 RNAi GmPrp17 transgenic events (Table 1). Furthermore, genomic PCR analysis indicated that both sense and antisense fragments were detected in samples of $\mathrm{T}_{1}$ transgenic plants (Fig. 2a, b), and RT-PCR for the GUS linker demonstrated that both RNAi constructs were expressed at the transcriptional level (Fig. 2c).

\section{Improved SCN resistance in soybeans transformed with RNAi constructs}

The phenotypes of the transgenic soybeans transformed with either of the two constructs resembled those of the non-transgenic cultivar JackX, which was the cultivar 
Table 1 Initial screening of SCN bioassays for all transgenic events $\left(T_{1}\right.$ seeds) for the elite line selection

\begin{tabular}{lc}
\hline Transgenic event & $\begin{array}{c}\text { Average reduc- } \\
\text { tion in eggs/root g } \\
\text { (mean } \pm \text { SEM) }\end{array}$ \\
\hline GmY25E5 & $50 \% \pm 10.6 \%^{\mathrm{a}}$ \\
GmY25E7 & $44 \% \pm 3.7 \%^{\mathrm{a}}$ \\
GmY25E12 & $59 \% \pm 6.4 \%^{\mathrm{a}}$ \\
GmY25E13 & $58 \% \pm 4.0 \%^{\mathrm{a}}$ \\
GmY25E1 & $6 \% \pm 2.2 \%$ \\
GmY25E3 & $13 \% \pm 2.7 \%$ \\
GmY25E4 & $26 \% \pm 14.4 \%$ \\
GmY25E6 & $0 \pm 3.6 \%$ \\
GmY25E10 & $11 \% \pm 11.3 \%$ \\
GmPrp17P1 & $72 \% \pm 9.2 \%^{\mathrm{a}}$ \\
GmPrp17P9 & $47 \% \pm 6.2 \%^{\mathrm{a}}$ \\
GmPrp17P6 & $53 \% \pm 8.1 \%^{\mathrm{a}}$ \\
GmPrp17P8 & $69 \% \pm 2.2 \%^{\mathrm{a}}$ \\
GmPrp17P7 & $24 \% \pm 6.2 \%$ \\
GmPrp17P2 & $-2 \% \pm 3.4 \%$ \\
GmPrp17P19 & $8 \% \pm 4.7 \%$ \\
\hline
\end{tabular}

Bioassay counts include only positive transgenic plants identified by PCR analysis. The reduction percentage is presented as mean \pm standard error of mean (SEM) based on three independent bioassay experiments and four biological replications for each transgenic line in each experiment, with experiments treated as a random effect

${ }^{a}$ Indicates that $t$ test was significant at $P \leq 0.05$

used for transformation. Some plants of the GmY25 lines, which displayed reduced vigor and/or were smaller than non-transgenic plants in the $\mathrm{T}_{1}$ generation, were subsequently withdrawn from further testing. To identify whether SCN reproduction was affected by the soybean transformation process, bioassays using soil infected with H. glycines HG type 7 and incorporating GOI-free transgenic (non-transformed segregated soybean identified by PCR) and non-transgenic JackX seeds as negative controls were performed in the greenhouse. Prior to the bioassay, the presence and expression of pANDA35HK-Y25 and pANDA35HK-Prp17 constructs were confirmed by PCR and RT-PCR for each individual transgenic plant. An initial screening of all $\mathrm{T}_{1}$ transgenic lines was conducted to select elite transgenic plants for further analysis. The initial screening bioassay results indicated that several lines showed significant differences in cysts/g root and eggs/g root (cyst and egg density, respectively) between transgenic plants and negative controls (data not shown). Four events of GmY25 and four events of GmPrp17 showed significant reduction $(P<0.05)$ for $\mathrm{SCN}$ egg numbers, compared to the negative control. At least five transgenic plants showed more than a 50\% reduction in eggs/g root (Table 1). Visibly fewer cysts were observed on the homozygous GmY25 and GmPrp17 transgenic roots, compared to negative controls (Fig. 3).

Based on the above results, two events of each RNAi construct (namely, GmY25E13, GmY25E5, GmPrp17P6, and GmPrp17P8) were selected for further analyses to investigate $\mathrm{SCN}$ resistance. The four GmY25 and GmPrp17 transgenic lines were taken to the $T_{2}$ and $T_{3}$ generation, respectively. To identify whether the elite transgenic soybean plants affected $H$. glycines reproduction, SCN bioassays were performed by growing these transgenic soybean plants, along with non-transgenic JackX plants as negative controls, in SCN HG type 7-infested soil. Both the GmPrp17P6 and P8 events showed a significant reduction in SCN populations averaging $69.3 \%$ and $73.3 \%$ in the egg density, respectively, compared to the control (Fig. 4, Table S5). Of the two GmY25 transgenic events evaluated (Fig. 4, Table S5), the GmY25E13 transgenic line showed a significantly reduced SCN population by $67.4 \%$ in the egg density. However, the GmY25E5 event did not affect the SCN population compared to the controls. The GOI-free plants, which were negative for target gene by PCR detection, showed similar SCN population levels as non-transgenic plants.

Two homozygous transgenic lines (GmY25E12 and GmY25E13) of GmY25 were advanced to the $\mathrm{T}_{3}$ generation, and two homozygous lines (GmPrp17P6, and GmPrp17P8) of $\mathrm{GmPrp} 17$ were taken to the $\mathrm{T}_{4}$ generation by self-pollination. To confirm homozygous lines with a single transgene insertion obtained, PCR analyses showed that the transgenes of all progenies in two generations were stably inherited. The transgene insert was confirmed by the segregation analysis using $\mathrm{T}_{1}$ generation (data not shown). To demonstrate consistent resistance to $\mathrm{SCN}$, bioassays in three independent experiments for each homozygous transgenic line were performed for these generations also showed significant reductions in cyst and egg densities consistently ranging from 42 to $73 \%$ (Fig. 5a, Table S6).

\section{Down-regulation of $\mathrm{HgY} 25$ and HgPrp17 transcripts in nematodes feeding on transgenic soybeans with corresponding RNAi constructs}

To determine whether the reduced SCN populations on the advanced transgenic lines (Fig. 5a) was due to the RNAi effects of inducing suppression of the targeted genes, total RNAs extracted from nematode eggs which were developed on homozygous transgenic and non-transgenic soybean roots at five weeks post-inoculation were analyzed for transcript abundance in each sample by qRT-PCR. Both targeted genes, HgY25 and HgPrp17, had down-regulated mRNA transcripts in nematode eggs collected from transgenic plant roots with the corresponding RNAi constructs (Fig. 5b). The highest (5.5 fold) reduction was observed on SCN feeding on GmPrp17P6 plants, whereas SCN on other events showed at 


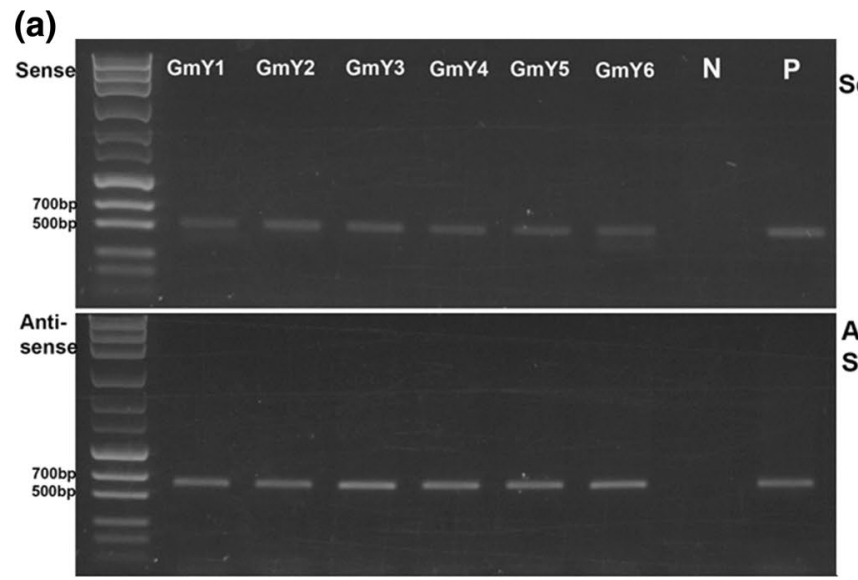

(b)

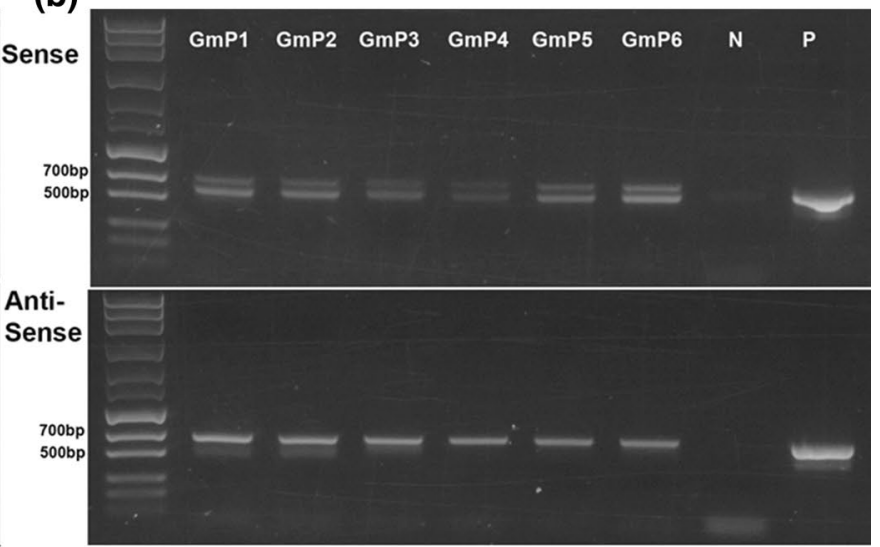

(c)

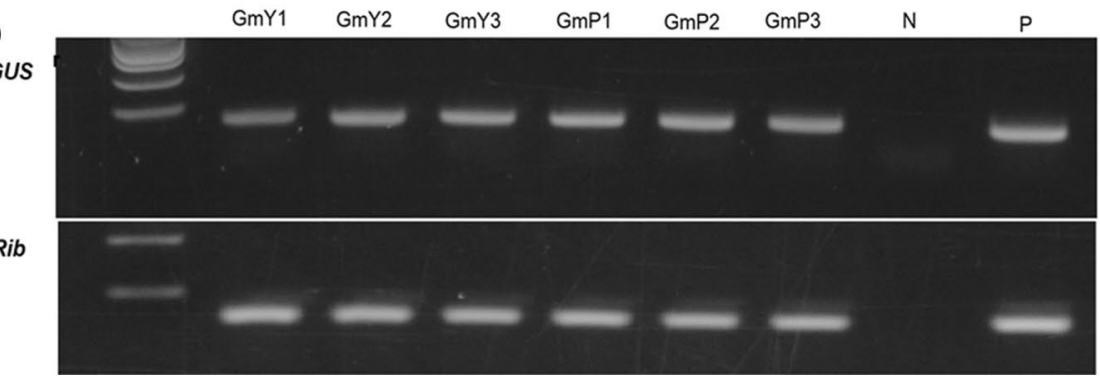

Fig. 2 Molecular analysis of RNAi-resistant transgenic (GmY25 and GmPrp17) soybean plants. a The amplification results of pANDA35HK-Y25 vector in soybean genomic DNA. The GUS-F1 and Y25 reverse primer pair and GUS-R2 and Y25 reverse primer pair were used to confirm both sense and antisense fragments presenting in the transgenic lines. GmY1-6 were six independent transgenic lines; $\mathrm{N}$ was non-transgenic soybean sample; and $\mathrm{P}$ was a control plasmid, pANDA35HK-Y25. b The amplification results of pANDA35HK-Prp17 vector in soybean genomic DNA. The GUSF1 and Prp17 reverse primer pair and GUS-R2 and Prp17 reverse

least a 3.4-fold reduction of transcripts with targeted genes. The decrease in the transcript levels of both parasite fitness genes was statistically significant $(P<0.05)$, whereas the transcript levels of non-target genes were not statistically changed (Fig. 5b). As expected, all the target genes displayed specific mRNA down-regulation in SCN populations recovered from transgenic plants with corresponding RNAi constructs.

\section{Detection of specific siRNAs in transgenic soybeans}

To evaluate the expression of siRNAs in transgenic plants, small RNA-seq libraries were prepared from leaf tissues and were sequenced by Illumina technology. The distribution of total unique siRNA sequences showed the highest abundance around the 21-nt length (Fig. S2), which was the same pattern as the dominant size of endogenous siRNA sequences of soybean reported in previous studies (Sun et al. 2016; Tian et al. 2017; Tuteja et al. 2009; Wang et al. 2013). primer pair were used to confirm both sense and antisense fragments presenting in the transgenic lines. GmP1-6 were six independent transgenic lines; $\mathrm{N}$ was non-transgenic soybean sample; and $\mathrm{P}$ was a control plasmid, pANDA35HK-Prp17. c RT-PCR analysis to detect the expression of GUS linker on RNAi construct; three lines from pANDA35HK-Y25 (GmY1-3) and pANDA35HK-Prp17 (GmP1-3) were exhibited; $\mathrm{N}$ was blank control, $\mathrm{P}$ was a control plasmid in GUS and was cDNA from non-transgenic soybean in Rib, which is soybean conserved Rib gene (Ribosomal-S21, CF921751) as control

Two RNAi constructs produced different siRNA profiles (Fig. 6). For the $\mathrm{HgY} 25$ gene (Fig. 6a), most siRNAs were produced from 125 to $270 \mathrm{nt}$ region of the $\mathrm{HgY} 25$ fragment with the highest counts in the 150-200 nt region. There were two further hot spot regions from 30-60 nt and 70-100 nt for HgY25 siRNA. The HgPrp17 gene (Fig. 6b) produced more concentrated regions at 200-260 nt and 310-350 nt. The data also indicated that siRNAs in HgPrp17 had more unified patterns than the HgY25. Compared across generations and diverse individual plants, the patterns for siRNAs expressed by RNAi constructs appeared to be conserved through generations, although the abundance of each siRNA varied in different samples (Fig. 6).

To investigate the potential relationship between the siRNA expression and SCN resistance, RNAs from individual heterozygous transgenic plants that showed different performance from the SCN bioassays as shown in Fig. 4 were used to prepare small RNA libraries. As shown in Table 2 for nine plants, the SCN reduction was higher in plants 


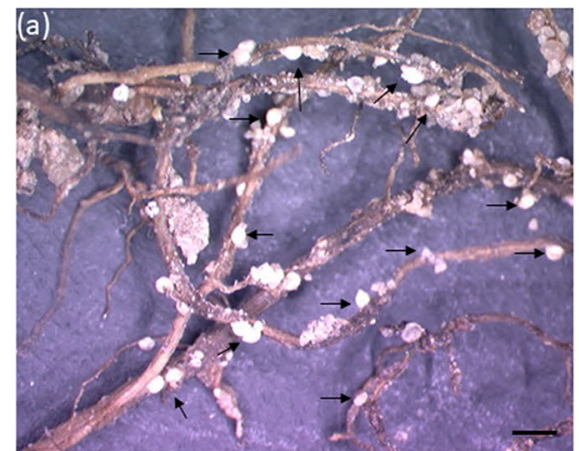

JackX (non-transgenic)
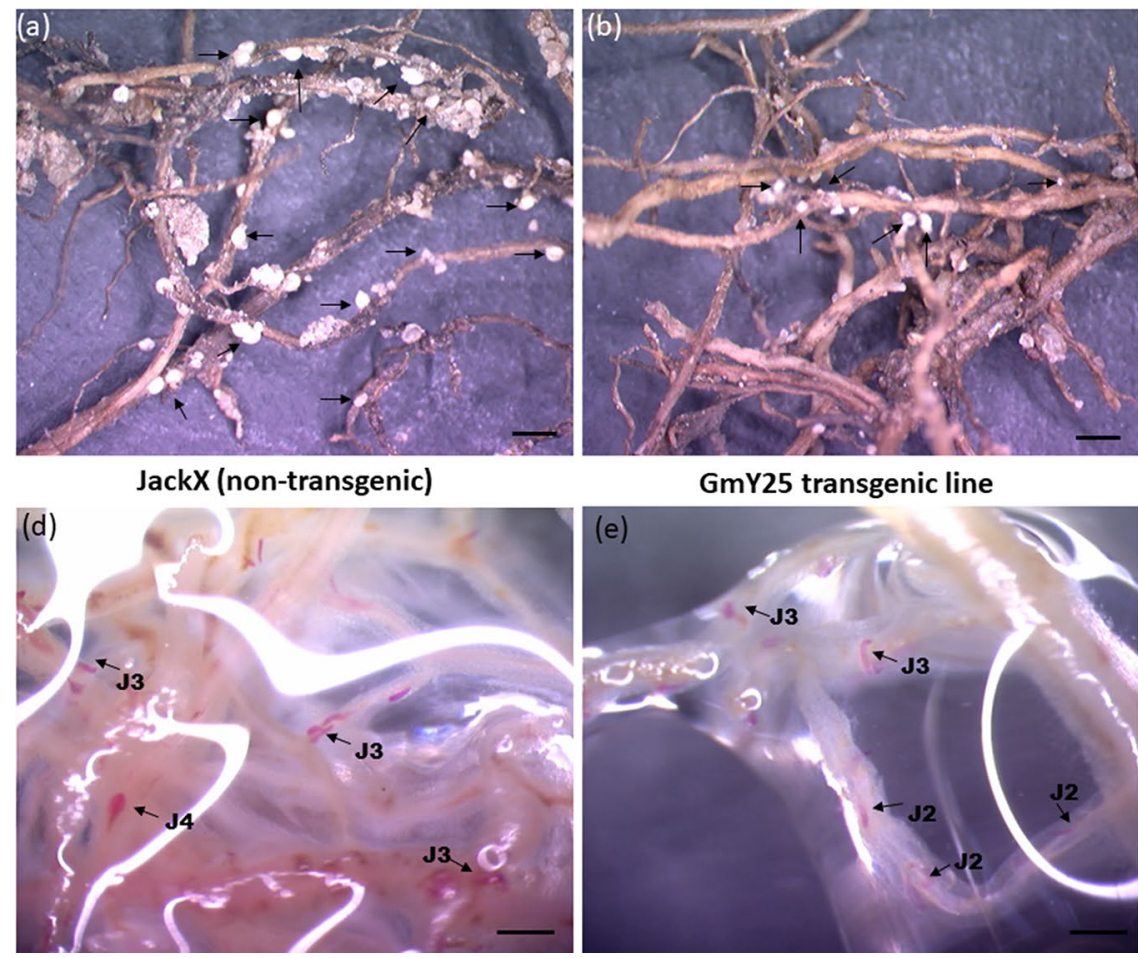

GmY25 transgenic line
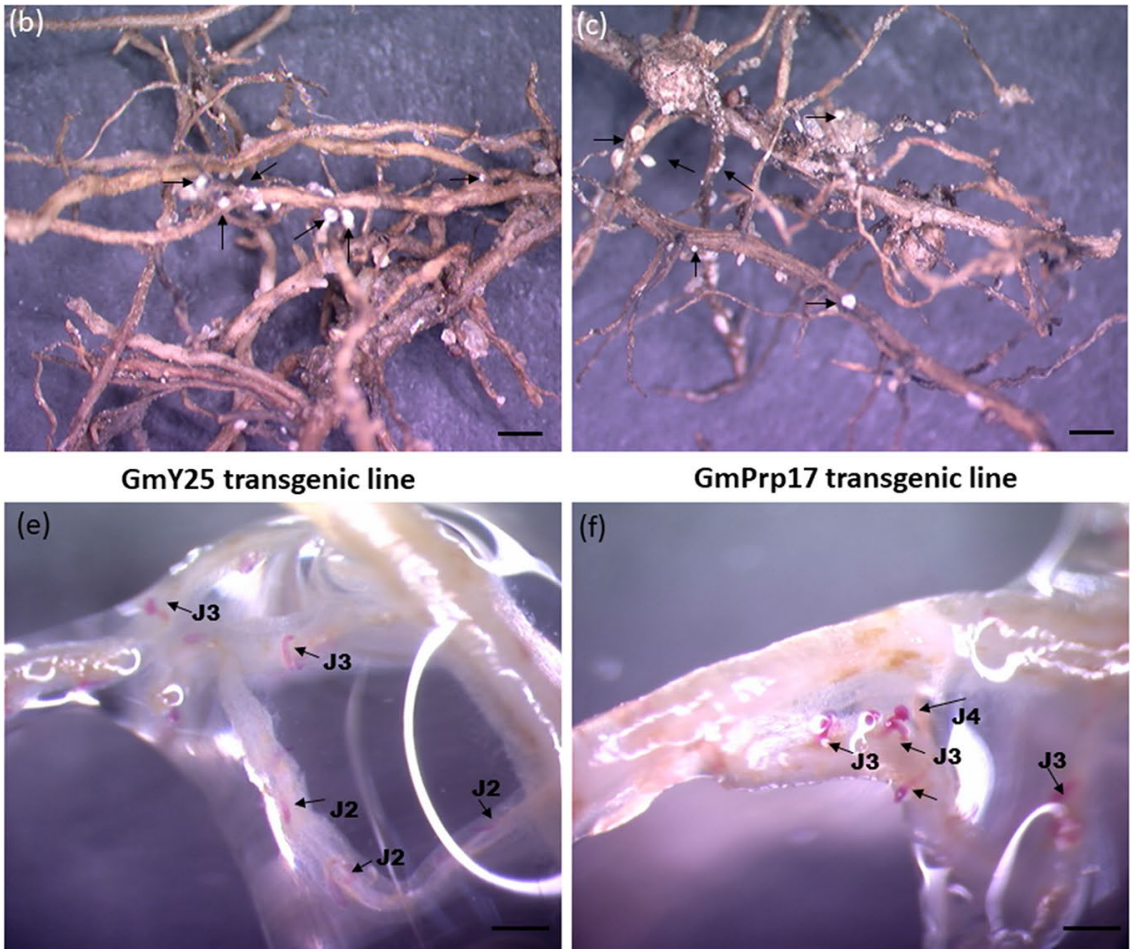

GmPrp17 transgenic line

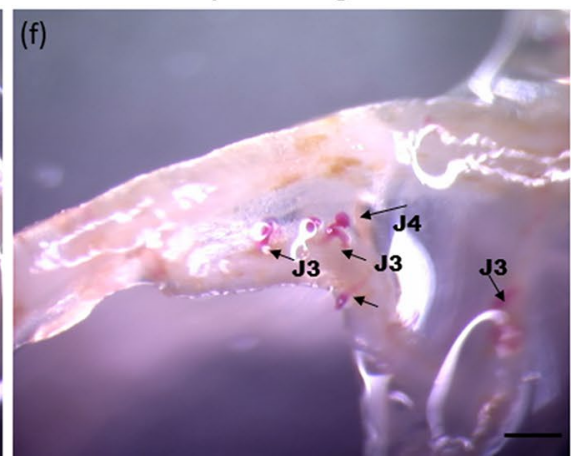

Fig. 3 Comparison of SCN population feeding on transgenic soybean and controls five weeks after inoculation. The homozygous transgenic plants from GmY25 $\left(\mathrm{T}_{4}\right)$ and GmPrp17 $\left(\mathrm{T}_{5}\right)$ were used. a, d Were non-transgenic controls; $\mathbf{b}$ and e were transgenic GmY25 RNAi plant with less cysts and juveniles on roots; $\mathbf{c}$ and $\mathbf{f}$ were transgenic
GmPrp17 RNAi plants with less cyst and juveniles on root. a-c Cysts were observed on the soybean roots under dissection microscopy; arrows indicated cysts. d-f Fuchsin staining of soybean roots for SCN visualization; arrows indicated all stages of juveniles. The scale bar represents $1 \mathrm{~mm}$ (a)

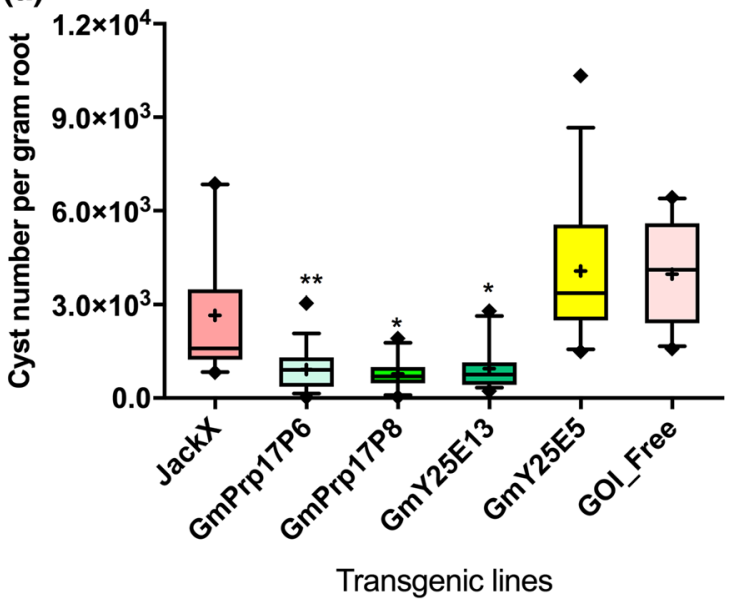

Fig. 4 Comparison of SCN cyst (a) and egg (b) densities developing on transgenic soybean roots and controls $(n=15)$. The $\mathrm{T}_{2}$ and $\mathrm{T}_{3}$ generation transgenic lines were used for GmY25 and GmPrp17, respectively. JackX was non-transgenic soybean, and the GOI-free line

with higher levels of small RNAs that matched the target (target RPM). Based on their performance in the bioassays (Fig. 5a), an independent experiment using RNAs from (b)

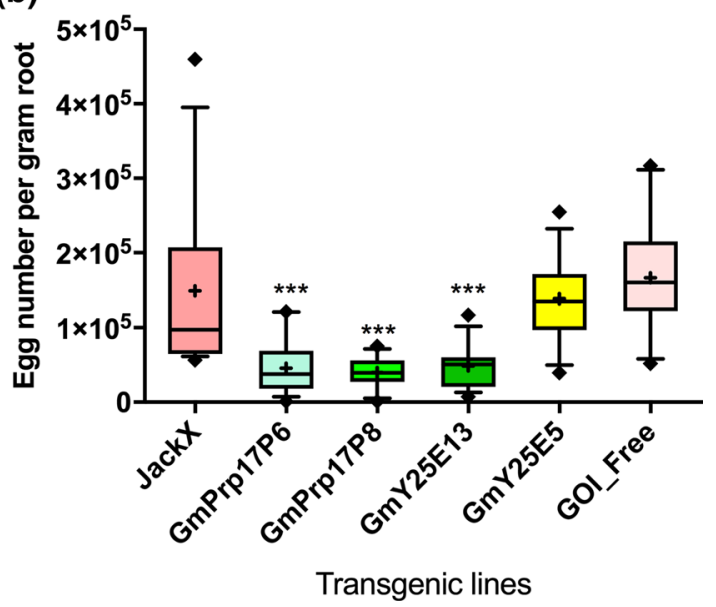

was negative for target gene by PCR detection. The mean value was shown as "+". The asterisks are significantly different from control JackX at $p<0.05(*), p<0.01(* *)$, and $p<0.001(* * *)$, respectively

homozygous transgenic lines GmY25E13 and GmPrp17P6 was conducted. A total of 12 libraries from each transgenic soybean line were constructed and analyzed (Table S4). As 


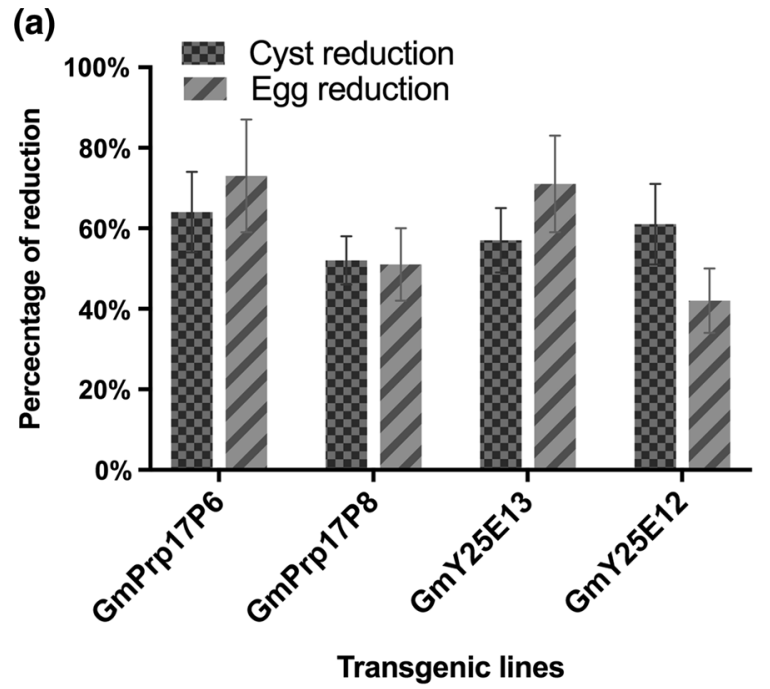

Fig. 5 Four homozygous lines (GmY25 and GmPrp17 are $\mathrm{T}_{3}$ and $\mathrm{T}_{4}$ generation) demonstrated reductions on SCN population with downregulated targeted genes. a Two homozygous lines for each GmY25 $(n=60)$ and GmPrp17 ( $n=60)$ showed significantly consistent reduction of SCN population compared to non-transgenic controls in three independent bioassays. Error bars represent the standard error of the mean based on three independent bioassays, with experiment treated as a random effect. b qRT-PCR was used for quantitating the expres-

shown in Fig. 7, it can be inferred from the data set that moderate to high levels of resistance to $\mathrm{SCN}$ [i.e., a reduction $>70 \%$ in SCN cyst and egg densities (Niblack et al. 2009)] were achieved with increasing small RNA levels, implying that a threshold level of target siRNAs needs to be expressed.

\section{Discussion}

Soybean production in the Midwestern USA is severely constrained by SCN, and the threat continues to spread (Mitchum 2016). The utilization of RNAi to engineer resistance to SCN provides alternative sources and strategies for advanced breeding. In vitro RNAi has been successfully used to silence target genes of plant parasitic nematodes (Dutta et al. 2014; Urwin et al. 2002), including H. glycines (Bakhetia et al. 2008). The objective of a host-derived RNAi strategy is to suppress nematode genes by delivery of the dsRNA and/or siRNA through the feeding apparatus, so that the development and/or reproduction of nematodes is disrupted and completion of their life cycle inside the plant host is prevented. For host-derived RNAi approaches, siRNAs for gene suppression are delivered continuously because obligate parasitic nematodes have to feed on their host plants throughout their life cycle (Li et al. 2011). This strategy was first demonstrated in transgenic tobacco where $90 \%$ suppression of root knot nematodes was obtained by targeting two (b)

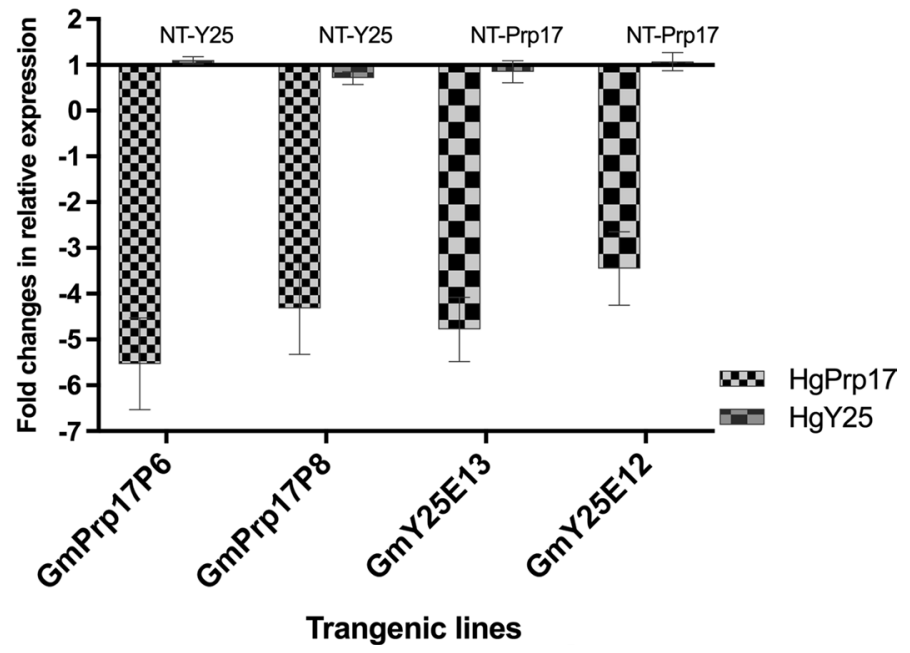

sion of target genes in SCN eggs collected from soybean roots, and the expression level was normalized to beta-actin gene in $H$. glycines. It showed the specific down-regulation of target HgY25 and HgPrp17 at transcription levels. The relative expression level of the non-target (NT) gene in each experiment remained unchanged. Error bars represent the standard error mean between three independent bioassay replicates

housekeeping genes (Yadav et al. 2006). Likewise, silencing of the major sperm protein in transgenic soybean successfully impaired the life cycle of cyst nematodes (Steeves et al. 2006). Since then, this host-derived RNAi strategy has been illustrated to reduce populations of various parasitic nematodes with different hosts (Dinh et al. 2014; Dutta et al. 2015; Klink et al. 2009; Kumar et al. 2017; Li et al. 2010; Lourenço-Tessutti et al. 2015; Papolu et al. 2013; Xue et al. 2013). The degree of reduction in nematode populations feeding on host plants is highly variable, however, depending on target genes, and host plant and parasite species. Minimal impacts on nematode populations have also been reported (Fairbairn et al. 2007; Kyndt et al. 2013; Patel et al. 2010; Sindhu et al. 2009; Vieira et al. 2015).

In this study, stable transgenic soybean lines targeting the SCN parasite fitness genes $\mathrm{HgY} 25$ and HgPrp17 were developed. Homozygous lines of each resulted in a better than $70 \%$ decrease in nematode egg densities. Based on high-throughput sequencing of small RNAs, a correlation between host-derived expression and resistance performance indicated that a threshold for siRNA expression needed to be achieved for effective suppression of parasite nematodes.

Nematode housekeeping genes are frequently targeted for RNAi suppression; however, targeting genes conserved in all eukaryotes may result in secondary effects that induce abnormal phenomena in the plant host (Bakhetia et al. 2008; Li et al. 2011; Schüssler et al. 2008). In the present study, no deviation from the normal growth phenotype was 

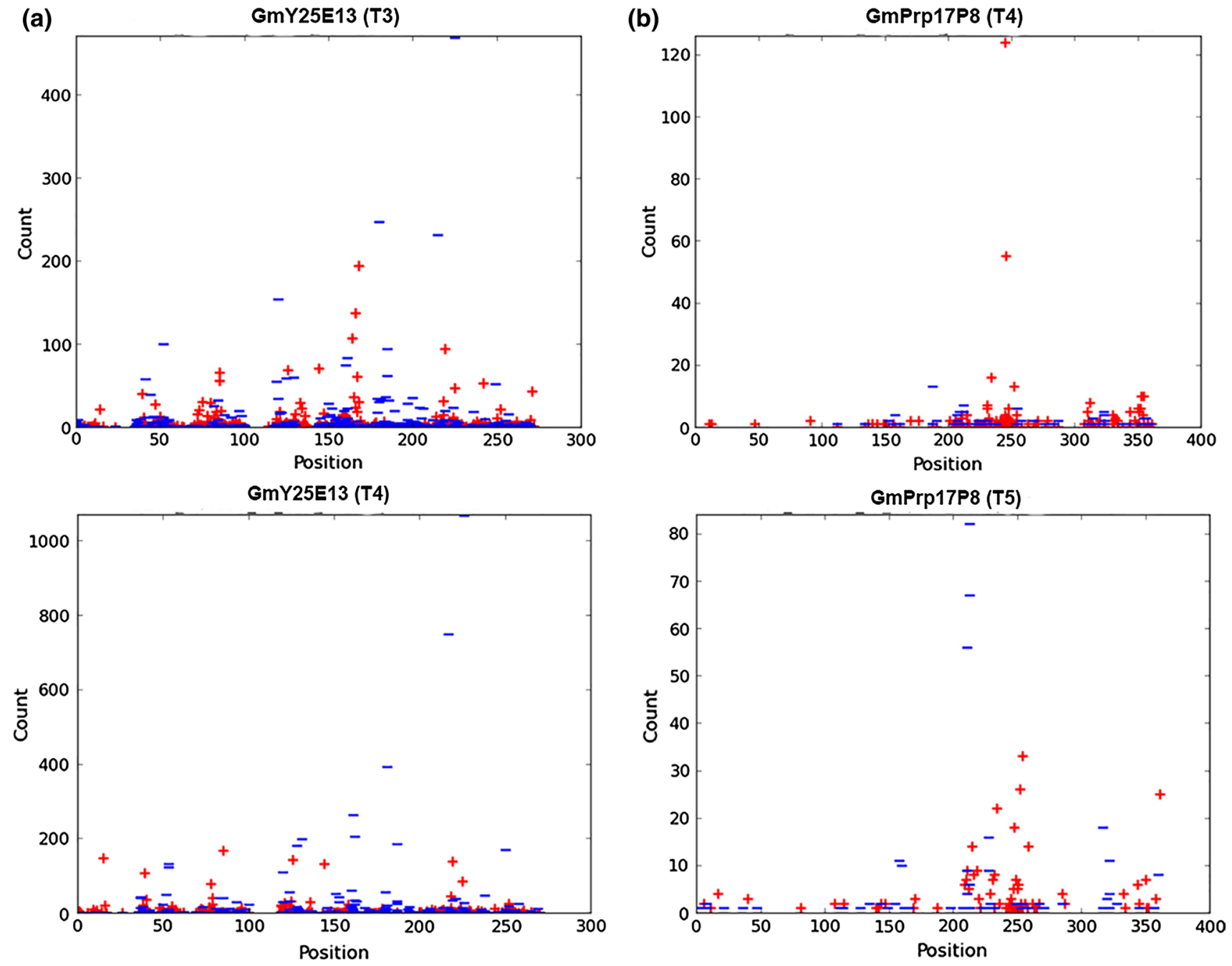

Fig. 6 The expressed siRNA distribution on target fragments of RNAi constructs in the transgenic plants GmY25E13 (a), and GmaPrp17P8 (b). The similar patterns were also observed from different generations of the same RNAi constructs. Counts and positions

Table 2 Small RNAs sequencing for target gene expression on individual transgenic plants $\left(T_{2}\right.$ generation for GmY25E13 plants, and $T_{3}$ generation for GmPrp17P6 and P8 plants were investigated) and corresponding effects on $\mathrm{SCN}$

\begin{tabular}{lllll}
\hline Transgenic lines & $\begin{array}{l}\text { Indi- } \\
\text { vidual } \\
\text { plant \# }\end{array}$ & $\begin{array}{l}\text { RPM } \\
\text { both } \\
\text { strand }\end{array}$ & $\begin{array}{l}\text { Cyst reduc- } \\
\text { tion percent- } \\
\text { age }\end{array}$ & $\begin{array}{l}\text { Egg reduction } \\
\text { percentage }\end{array}$ \\
\hline GmPrp17P6 & 1 & 845 & 65 & 69 \\
& 2 & 152 & 60 & 74 \\
& 3 & 46 & 29 & 35 \\
GmPrp17P8 & 1 & 191 & 53 & 68 \\
& 2 & 51 & 5 & 36 \\
GmY25E13 & 1 & 204 & 50 & 78 \\
& 2 & 210 & 65 & 66 \\
& 3 & 739 & 83 & 82 \\
& 4 & 701 & 78 & 78 \\
\hline
\end{tabular}

of siRNAs with lengths between 18-25 nucleotides that had a $100 \%$ match with either the positive (+) or negative (-) strand of the Y25 or Prp17 targets are shown

observed in the GmPrp17 transgenic lines. However, in some of GmY25 lines, smaller plants were observed. The germinated transgenic plants had shorter hypocotyls and fewer lateral roots than the non-transgenic plants; furthermore, the transgenic plants had fewer or almost no root hairs. This morphology may have resulted from potential off-target effects on the soybean host plant. Therefore, only GmY25 plants with normal phenotype were selected for advanced experimentation in this study.

Small RNA sequencing of transgenic plants expressing RNAi vectors for nematode resistance could provide insight into populations of siRNA species generated, and their utility for silencing SCN genes effectively. The siRNA sequencing results also indicated that a soybean dicer-like protein (DCL) was cleaving the $H$. glycines genes' dsRNAs into 19-24 nt nucleotides, with similar patterns as observed for 
(a)

GmY25

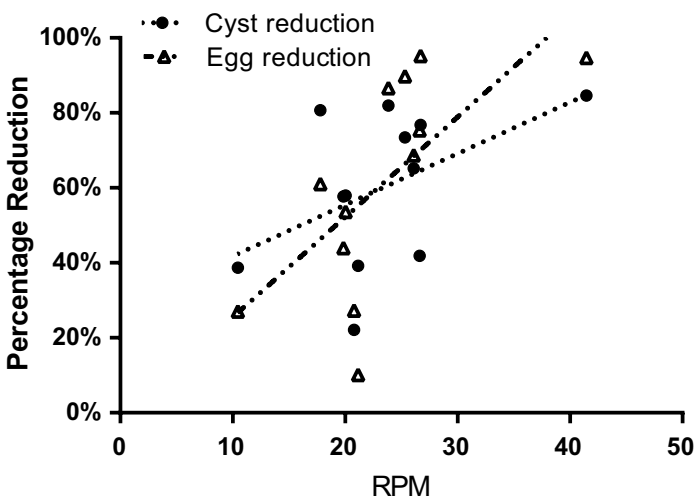

Fig. 7 The putative relationships between siRNA expression (RPM) of RNAi constructs and the effectiveness of SCN resistance (percentage reduction in cyst and egg numbers) for 12 homozygous transgenic plants each for events GmY25E13 (a) and GmPrp17P6 (b). Linear regression equations for $\mathrm{GmY} 25 \mathrm{E} 13$ were $\mathrm{Y}=28.12+1.37 \mathrm{X}$

endogenous siRNA. Our results showed that the predominant size of siRNAs was 21-nt, the same as the dominant size of endogenous siRNA sequences of soybean reported by Tuteja et al. (2009), demonstrating that the cleaving mechanism of soybean DCL was likely the same for endogenous and exogenous genes. The target genes in nematodes feeding on transgenic soybean plants were correspondingly suppressed to a significant extent (Fig. 5b), thus providing evidence of effective delivery of siRNA and/or dsRNA into nematodes. The distribution of target siRNA with the same constructs followed similar patterns over generations. Based on smRNA sequencing of individual transgenic plants, it was hypothesized that siRNA levels were related to resistance. The RNA-seq analysis of siRNA in planta strongly suggested a threshold of RNAi construct expression level was related to the SCN resistance of the transgenic plant (Fig. 7). Either of the two RNAi constructs needed to reach the threshold concentration in transgenic plants to bring about effective reductions (defined as $>70 \%$ in present study) in nematode numbers. The results of this study support a growing body of evidence indicating that a host-derived RNAi strategy can be an effective approach for SCN management. The quantity of siRNA produced in the host plant is one of the major factors limiting the success of resistance. Future studies will investigate ways to increase siRNA expression, using high expression promoters, and/or vectors in soybean, or by manipulating siRNA amplification pathways. In addition, stacking two or more RNAi cassettes may provide host plants with additional, as well as more durable, levels of resistance against parasitic nematodes.

Author contribution statement BT and HNT designed the experiments and wrote the manuscript. BT designed

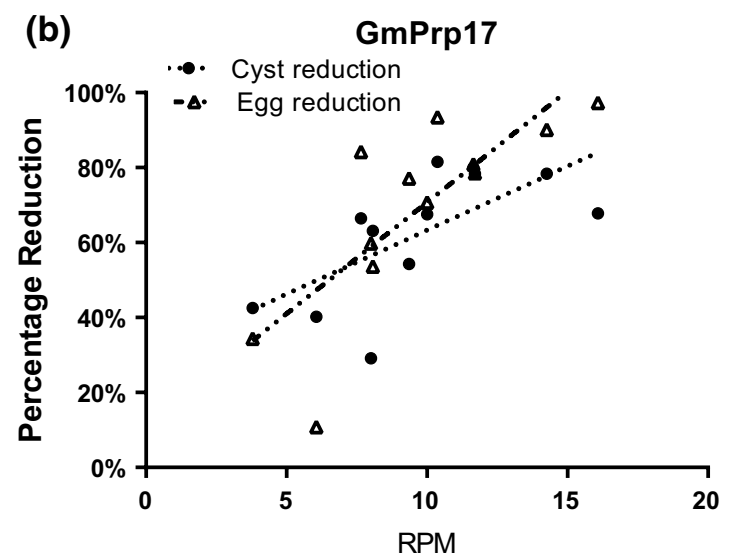

$\left(P=0.1079, r^{2}=0.24\right)$ for cysts and $\mathrm{Y}=-1.09+2.67 \mathrm{X}(P=0.0162$, $\left.r^{2}=0.45\right)$ for eggs. Linear regression equations for GmPrp17P6 were $\mathrm{Y}=29.21+3.40 \mathrm{X} \quad\left(P=0.0174, \quad r^{2}=0.45\right) \quad$ for cysts and $\mathrm{Y}=11.57+5.91 \mathrm{X}\left(P=0.0025, r^{2}=0.61\right)$ for eggs

and conducted experiments including SCN bioassays with statistical analyses, real-time PCR with data analyses, and prepared the RNA-seq samples. JL cloned the HgY25 gene and constructed vectors. LOV performed the RNA-seq and assisted the data analyses. TCT supported the SCN bioassay and participated in statistical analyses and revised the manuscript. JJF developed the $\mathrm{T}_{0}$ stable transgenic soybean lines and revised the manuscript. HNT designed the experiments, coordinated project, analyzed data, and wrote the manuscript.

Acknowledgements The authors would like to thank Dr. Wayne A. Parrott's laboratory for their generous help with soybean seeds, and transgenic soybean production. Authors thank Thomas R. Oakley at Kansas State University for maintaining and providing SCN inoculation sources. This research was supported by Kansas Soybean Commission and North Central Soybean Research Program. This article is contribution no. 18-302-J from the Kansas Agricultural Experimental Station, Kansas State University, Manhattan, KS. HNT and TCT are listed as inventors of US Patents 7803984 and 9297022.

\section{Compliance with ethical standards}

Conflict of interest The authors declare that they have no conflict of interest.

Open Access This article is distributed under the terms of the Creative Commons Attribution 4.0 International License (http://creativeco mmons.org/licenses/by/4.0/), which permits unrestricted use, distribution, and reproduction in any medium, provided you give appropriate credit to the original author(s) and the source, provide a link to the Creative Commons license, and indicate if changes were made. 


\section{References}

Alkharouf NW, Klink VP, Matthews BF (2007) Identification of Heterodera glycines (soybean cyst nematode [SCN]) cDNA sequences with high identity to those of Caenorhabditis elegans having lethal mutant or RNAi phenotypes. Exp Parasitol 115:247-258

Bakhetia M, Urwin PE, Atkinson HJ (2008) Characterisation by RNAi of pioneer genes expressed in the dorsal pharyngeal gland cell of Heterodera glycines and the effects of combinatorial RNAi. Int J Parasitol 38:1589-1597

Bolognesi R, Ramaseshadri P, Anderson J, Bachman P, Clinton W, Flannagan R, Ilagan O, Lawrence C, Levine S, Moar W, Mueller G, Tan J, Uffman J, Wiggins E, Heck G, Segers G (2012) Characterizing the mechanism of action of double-stranded RNA activity against western corn rootworm (Diabrotica virgifera virgifera LeConte). PLoS ONE 7:e47534

Cheng W, Song XS, Li HP, Cao LH, Sun K, Qiu XL, Xu YB, Yang P, Huang T, Zhang JB, Qu B, Liao YC (2015) Host-induced gene silencing of an essential chitin synthase gene confers durable resistance to Fusarium head blight and seedling blight in wheat. Plant Biotechnol J 13:1335-1245

Dinh PTY, Brown CR, Elling AA (2014) RNA interference of effector gene Mc16D10L confers resistance against meloidogyne chitwoodi in arabidopsis and potato. Phytopathology 104:1098-1106

Dutta TK, Banakar P, Rao U (2014) The status of RNAi-based transgenic research in plant nematology. Front Microbiol 5:760

Dutta TK, Papolu PK, Banakar P, Choudhary D, Sirohi A, Rao U (2015) Tomato transgenic plants expressing hairpin construct of a nematode protease gene conferred enhanced resistance to rootknot nematodes. Front Microbiol 6:260

Fairbairn DJ, Cavallaro AS, Bernard M, Mahalinga-Iyer J, Graham MW, Botella JR (2007) Host-delivered RNAi: an effective strategy to silence genes in plant parasitic nematodes. Planta 226:1525-1533

Finer JJ, McMullen MD (1991) Transformation of soybean via particle bombardment of embryogenic suspension culture tissue. Vitro Cell Dev Biol Plant 27:175-182

Finer JJ, Vain P, Jones MW, McMullen MD (1992) Development of the particle inflow gun for DNA delivery to plant cells. Plant Cell Rep 11:323-328

Fire A, Xu S, Montgomery MK, Kostas SA, Driver SE, Mello CC (1998) Potent and specific genetic interference by double-stranded RNA in Caenorhabditis elegans. Nature 391:806-811

Gillet F-X, Bournaud C, de Souza Antonino, Júnior JD, Grossi-deSa MF (2017) Plant-parasitic nematodes: towards understanding molecular players in stress responses. Ann Bot 119:775-789

Govindarajulu M, Epstein L, Wroblewski T, Michelmore RW (2015) Host-induced gene silencing inhibits the biotrophic pathogen causing downy mildew of lettuce. Plant Biotechnol J 13:875-883

Huang G, Allen R, Davis EL, Baum TJ, Hussey RS (2006) Engineering broad root-knot resistance in transgenic plants by RNAi silencing of a conserved and essential root-knot nematode parasitism gene. Proc Natl Acad Sci 103:14302-14306

Kamath RS, Fraser AG, Dong Y, Poulin G, Durbin R, Gotta M, Kanapin A, Le Bot N, Moreno S, Sohrmann M, Welchman D, Zipperlen P, Ahringer J (2003) Systematic functional analysis of the Caenorhabditis elegans genome using RNAi. Nature 421:231-237

Kerins JA, Hanazawa M, Dorsett M, Schedl T (2010) PRP-17 and the pre-mRNA splicing pathway are preferentially required for the proliferation versus meiotic development decision and germline sex determination in Caenorhabditis elegans. Dev Dyn 239(5):1555-1572
Klink VP, Matthews BF (2009) Emerging approaches to broaden resistance of soybean to soybean cyst nematode as supported by gene expression studies. Plant Physiol 151:1017-1022

Klink VP, Kim K-H, Martins V, MacDonald MH, Beard HS, Alkharouf NW, Lee S-K, Park S-C, Matthews BF (2009) A correlation between host-mediated expression of parasite genes as tandem inverted repeats and abrogation of development of female Heterodera glycines cyst formation during infection of Glycine max. Planta 230:53-71

Koenning, S.R. and Wrather, J.A. (2010) Suppression of soybean yield potential in the continental United States from plant diseases estimated from 2006 to 2009. Plant Health Prog. https:// doi.org/10.1094/PHP-2010-1122-01-RS

Kumar A, Kakrana A, Sirohi A, Subramaniam K, Srinivasan R, Abdin MZ, Jain PK (2017) Host-delivered RNAi-mediated root-knot nematode resistance in Arabidopsis by targeting splicing factor and integrase genes. J Gen Plant Pathol 83:91-97

Kyndt T, Ji H, Vanholme B, Gheysen G (2013) Transcriptional silencing of RNAi constructs against nematode genes in Arabidopsis. Nematology 15:519-528

Langmead B, Trapnell C, Pop M, Salzberg SL (2009) Ultrafast and memory-efficient alignment of short DNA sequences to the human genome. Genome Biol 10:R25

Li J, Todd TC, Trick HN (2009) Rapid in planta evaluation of root expressed transgenes in chimeric soybean plants. Plant Cell Rep 29:113-123

Li J, Todd TC, Oakley TR, Lee J, Trick HN (2010) Host-derived suppression of nematode reproductive and fitness genes decreases fecundity of Heterodera glycines Ichinohe. Planta 232:775-785

Li J, Todd TC, Lee J, Trick HN (2011) Biotechnological application of functional genomics towards plant-parasitic nematode control. Plant Biotechnol J 9:936-944

Liu S, Kandoth PK, Lakhssassi N, Kang J, Colantonio V, Heinz R, Yeckel G, Zhou Z, Bekal S, Dapprich J, Rotter B, Cianzio S, Mitchum MG, Meksem K (2017) The soybean GmSNAP18 gene underlies two types of resistance to soybean cyst nematode. Nat Commun 8:14822

Livak KJ, Schmittgen TD (2001) Analysis of relative gene expression data using real-time quantitative PCR and the $2^{-\Delta \Delta C T}$ method. Methods 25:402-408

Lourenço-Tessutti IT, Souza Junior JDA, Martins-de-Sa D, Viana AAB, Carneiro RMDG, Togawa RC, de Almeida-Engler J, Batista JAN, Silva MCM, Fragoso RR, Grossi-de-Sa MF (2015) Knockdown of heat-shock protein 90 and isocitrate lyase gene expression reduced root-knot nematode reproduction. Phytopathology 105:628-637

Miki D, Shimamoto K (2004) Simple RNAi vectors for stable and transient suppression of gene function in rice. Plant Cell Physiol 45:490-495

Mitchum MG (2016) Soybean resistance to the soybean cyst nematode Heterodera glycines: an update. Phytopathology 106:1444-1450

Niblack T, Tylka GL, Arelli P, Bond J, Diers B, Donald P, Faghihi J, Ferris VR, Gallo K, Heinz RD, Lopez-Nicora H, Von Qualen R, Welacky T, Wilcox J (2009) A standard greenhouse method for assessing soybean cyst nematode resistance in soybean: SCE08 (standardized cyst evaluation 2008). Plant Health Prog. https:// doi.org/10.1094/PHP-2009-0513-01-RV

Nickel W, Brügger B, Wieland FT (2002) Vesicular transport: the core machinery of COPI recruitment and budding. J Cell Sci 115:3235-3240

Papolu PK, Gantasala NP, Kamaraju D, Banakar P, Sreevathsa R, Rao U (2013) Utility of host delivered RNAi of two FMRF amide like peptides, flp-14 and flp-18, for the management of root knot nematode meloidogyne incognita. PLoS ONE 8:e80603 
Patel N, Hamamouch N, Li C, Hewezi T, Hussey RS, Baum TJ, Mitchum MG, Davis EL (2010) A nematode effector protein similar to annexins in host plants. J Exp Bot 61:235-248

Sanju S, Siddappa S, Thakur A, Shukla PK, Srivastava N, Pattanayak D, Sharma S, Singh BP (2015) Host-mediated gene silencing of a single effector gene from the potato pathogen Phytophthora infestans imparts partial resistance to late blight disease. Funct Integr Genom 15:697-706

Schüssler MD, Alexandersson E, Bienert GP, Kichey T, Laursen KH, Johanson U, Kjellbom P, Schjoerring JK, Jahn TP (2008) The effects of the loss of TIP1;1 and TIP1;2 aquaporins in Arabidopsis thaliana. Plant J 56:756-767

Sindhu AS, Maier TR, Mitchum MG, Hussey RS, Davis EL, Baum TJ (2009) Effective and specific in planta RNAi in cyst nematodes: expression interference of four parasitism genes reduces parasitic success. J Exp Bot 60:315-324

Sobezak M, Golinowski W (2009) Structure of cyst nematode feeding sites. In: Berg RH, Taylor CG (eds) Plant cell monographs. Springer, Berlin

Steeves RM, Todd TC, Essig JS, Trick HN (2006) Transgenic soybeans expressing siRNAs specific to a major sperm protein gene suppress Heterodera glycines reproduction. Funct Plant Biol 33:991-999

Sun Z, Wang Y, Mou F, Tian Y, Chen L, Zhang S, Jiang Q, Li X (2016) Genome-wide small RNA analysis of soybean reveals auxin-responsive microRNAs that are differentially expressed in response to salt stress in root Apex. Front Plant Sci 6:1273. https ://doi.org/10.3389/fpls.2015.01273

Tian B, Li J, Oakley T, Todd T, Trick H (2016) Host-derived artificial microrna as an alternative method to improve soybean resistance to soybean cyst nematode. Genes 7:122

Tian B, Wang S, Todd TC, Johnson CD, Tang G, Trick HN (2017) Genome-wide identification of soybean microRNA responsive to soybean cyst nematodes infection by deep sequencing. BMC Genom 18:572

Trick HN, Dinkins RD, Santarem ER, Di R, Samoylov V, Meurer CA, Walker DR, Parrott WA, Finer JJ, Collins GB (1997) Recent advances in soybean transformation. Plant Tissue Cult Biotechnol 3:9-26

Tuteja JH, Zabala G, Varala K, Hudson M, Vodkin LO (2009) Endogenous, tissue-specific short interfering RNAs silence the chalcone synthase gene family in 'Glycine max' seed coats. Plant Cell 21:3063-3077

Urwin PE, Lilley CJ, Atkinson HJ (2002) Ingestion of double-stranded RNA by preparasitic juvenile cyst nematodes leads to RNA interference. Mol Plant Microbe Interact 15:747-752

Vieira P, Eves-van den Akker S, Verma R, Wantoch S, Eisenback JD, Kamo K (2015) The Pratylenchus penetrans transcriptome as a source for the development of alternative control strategies: mining for putative genes involved in parasitism and evaluation of in planta RNAi. PLoS ONE 10:e0144674

Wang Y, Zhang C, Hao Q, Sha A, Zhou R, Zhou X, Yuan L (2013) Elucidation of miRNAs-mediated responses to low nitrogen stress by deep sequencing of two soybean genotypes. PLoS ONE 8:e67423

Xue B, Hamamouch N, Li C, Huang G, Hussey RS, Baum TJ, Davis EL (2013) The 8D05 parasitism gene of meloidogyne incognita is required for successful infection of host roots. Phytopathology 103:175-181

Yadav BC, Veluthambi K, Subramaniam K (2006) Host-generated double stranded RNA induces RNAi in plant-parasitic nematodes and protects the host from infection. Mol Biochem Parasitol 148:219-222

Zhang J, Khan SA, Hasse C, Ruf S, Heckel DG, Bock R (2015) Full crop protection from an insect pest by expression of long doublestranded RNAs in plastids. Science 347:991-994

Publisher's Note Springer Nature remains neutral with regard to jurisdictional claims in published maps and institutional affiliations. 